\title{
Nuclear Reprogramming Strategy Modulates Differentiation Potential of Induced Pluripotent Stem Cells
}

\author{
Almudena Martinez-Fernandez • Timothy J. Nelson • \\ Andre Terzic
}

Received: 17 September 2010 / Accepted: 17 November 2010 /Published online: 5 January 2011

(C) The Author(s) 2011. This article is published with open access at Springerlink.com

\begin{abstract}
Bioengineered by ectopic expression of stemness factors, induced pluripotent stem (iPS) cells demonstrate embryonic stem cell-like properties and offer a unique platform for derivation of autologous pluripotent cells from somatic tissue sources. In the process of nuclear reprogramming, somatic tissues are converted to a pluripotent ground state, thus unlocking an unlimited potential to expand progenitor pools. Molecular dissection of nuclear reprogramming suggests that a residual memory derived from the original parental source, along with the remnants of the reprogramming process itself, leads to a biased potential of the bioengineered progeny to differentiate into target tissues such as cardiac cytotypes. In this way, iPS cells that fulfill pluripotency criteria may display heterogeneous profiles for lineage specification. Small molecule-based strategies have been identified that modulate the epigenetic state of reprogrammed cells and are optimized to erase the residual memory and homogenize the differentiation potential of iPS cells derived from distinct backgrounds. Here, we describe the salient components of the reprogramming process and their effect on the downstream differentiation capacity of the iPS populations in the context of cardiovascular regenerative applications.
\end{abstract}

Keywords iPS · Epigenetic memory - Differentiation capacity $\cdot$ Memory-free pluripotency

\footnotetext{
A. Martinez-Fernandez • T. J. Nelson · A. Terzic $(\bowtie)$

Marriott Heart Disease Research Program,

Division of Cardiovascular Diseases,

Departments of Medicine and Molecular Pharmacology

and Experimental Therapeutics, Mayo Clinic,

200 First Street SW,

Rochester, MN 55905, USA

e-mail: terzic.andre@mayo.edu
}

\section{Introduction}

Pluripotent cells have the capacity of differentiating towards cell types from the three germinal layers of the body while holding a high replication potential. In this way, embryonic stem cells derived in the 1980s (mouse) [1] and 1990s (human) [2] revolutionized biomedical research, offering the possibility to produce de novo tissues that could be used to replace or regenerate diseased organs; however, ethical concerns and host/donor immunological mismatch have contributed to the hurdles that challenge clinical applications.

A paradigm shift within the field of regenerative medicine occurred in 2006 with the derivation of pluripotent cells from somatic fibroblasts by transduction with a set of four transcription factors [3]. Uniquely, this platform eliminates the need for embryonic tissue and opens a new avenue for personalized drug testing, diagnosis, and therapy $[4,5]$. Studies that followed have optimized the derivation of induced pluripotent stem (iPS) cells from human somatic sources [6-13] and have refined this process to increase reprogramming efficiency [14-17]. Also, numerous protocols have been described to guide differentiation of these bioengineered pluripotent cells into diverse cell types useful for broad applications in discovery and translational science [18-26]. Notably, specialized cardiovascular lineages derived through the process of nuclear reprogramming of healthy and/or diseased somatic tissues have been applied across the continuum of biomedical applications [27-30].

The opportunity to refine tissue-specific differentiation protocols by identifying the appropriate somatic tissue source and reprogramming strategy would accelerate the field of cardiovascular regenerative biology. Based on the epigenetic and transcriptional carryover that follows reprogramming, a residual memory may be influenced by both tissue of origin 
[31] and the reprogramming process $[32,33]$. The impact of this memory will likely be dependent on the use or application of the bioengineered iPS cells while understanding the determinants of residual memory may lead to targeted optimization of the reprogramming process.

\section{Tissue of Origin}

Original studies on nuclear reprogramming by viral transduction utilized murine embryonic fibroblasts $[3,34$, 35], a cell commonly used in stem cell biology, to bioengineer a pluripotent state from a somatic cytotype; however, the embryonic origin of these cells raised the possibility for contamination with pluripotent progenitors rather than bona fide reprogramming [36]. This scientific uncertainty was addressed by applying adult fibroblasts as alternative starting material to generate pluripotent stem cells [37]. These somatic cells were also amenable to reprogramming, demonstrating that pluripotent ground state can be reset in adult-derived cells that were previously fully committed to a defined phenotype [38]. A broad array of cell types have subsequently been used as tissue source, including other adult somatic tissues such as dermal skin [39, 40], liver/ stomach biopsy [41], beta cells from the pancreas [42], as well as neural [43, 44], and hematopoietic cells [45]. The possibility of reprogramming somatic cells derived from different starting tissues at similar efficiency rates would support a stochastic model in which reprogramming a pluripotent state was limited by time and not inherent to the starting cell type [46]. In this way, all donor cells, regardless of their tissue origin, eventually could be reset to the pluripotent state upon continuous overexpression of stemness-related genes. This finding, in contrast to an elite model that suggests that only a specific subpopulation of progenitor cells could be completely reprogrammed [47], indicated that differentiation is a fully reversible process; however, it has also been shown that distinct tissue types have various bioengineering requirements to ensure full reprogramming towards the pluripotent ground state. A case in point, stomach epithelium and hepatocytes require lower levels of reprogramming factors to achieve pluripotency, thus offering an advantage to bioengineer ectopic expression with alternative delivery strategies [41].

Despite the "universal" reprogramming theory that enables a wide pool of starting cell sources, comparison of reprogrammed pluripotent cells derived from distinct tissues unmasked differences in the in vivo differentiation and growth capacity. In this regard, mouse adult tail tip fibroblasts and adult hepatocytes have demonstrated the highest risk of dysregulated teratoma formation when injected into immunodeficient mice in contrast to iPS cells derived from embryonic fibroblasts or stomach epithelium characterized by a lower teratogenic propensity similar to embryonic stem cells [48]. Thus, residual molecular profiles, inherent to source tissue, do apparently determine the phenotypic outcome upon in vivo transplantation into a permissive environment.

In human cells, successful reprogramming has also been possible using several starting tissue sources that include, beyond dermal skin [6, 7], keratinocytes [8], adipose tissue [9], and peripheral blood [10-13]. Furthermore, nuclear reprogramming by transcription factor transduction has been used to obtain pluripotent cells derived from patients. iPS cells have been generated from both genetic and noninheritable diseases, including Parkinson's disease, Duchenne muscular dystrophy, Becker's muscular dystrophy, Down's syndrome, Huntington's disease [49], myeloproliferative disorders [50], amyotrophic lateral sclerosis [51], Fanconi's anemia [52], type 1 diabetes [23], spinal muscular atrophy [53], familial dysautonomia [54], LEOPARD syndrome [27], and long QT syndrome [28]. In cardiovascular applications, patient-specific iPS cells have been used to identify molecular causes of disease deepening our understanding of various cardiac syndromes and demonstrating the usefulness of this platform as a translational discovery tool. In particular, long QT syndrome patient dermal fibroblasts have been reprogrammed and subsequently differentiated into cardiomyocytes that were shown to display characteristic phenotypes recapitulating molecular features of the disease [28]. A detailed characterization and comparison with cells derived from healthy relatives led to significant discoveries regarding the molecular causes of this disease and allowed for therapeutic protective drug testing in vitro [28]. In a similar way, molecular features of hypertrophic cardiomyopathy found in patients with LEOPARD syndrome have also been recapitulated in vitro using iPS cells coupled with cardiac differentiation protocols [27]. Therefore, iPS cell technology permits patient-specific and in vitro studies not possible from other sources of primary human cells [27, 28].

Therapeutic application of iPS cells has also been tested in cardiac disease revealing the capacity to rescue morphological and functional physiological parameters in vivo in a model of acute ischemic injury to the myocardium [29]. In fact, reprogrammed cells injected at the site of infarction show engraftment for several weeks together with physical and physiological integration within the host tissue [29]. Cells corresponding to all three cardiac lineages (cardiomyocytes, smooth muscle, and endothelium) can be derived from the injected iPS cells, contributing to a reduced fibrotic scar as well as to the recovery of the functional parameters representative of cardiac performance [29]. Therefore, reprogramming somatic cells into functional pluripotent stem cells demonstrates the ability to produce cardiac regeneration from ordinary tissue sources [29]. 
In addition to therapeutic studies, multiple reports have consistently demonstrated the cardiac differentiation potential of iPS cells in vitro (Table 1). Beyond first approximation of gene expression, structural characterization and beating activity originally used as landmarks of cardiac differentiation $[20,21,29,55,56]$, functional parameters such as electrophysiological characterization, force measurements, and drug regulation have emerged as a critical component defining the cardiogenic potential of iPS cells [57-64].

The application of iPS technology as a tissue-specific discovery platform, diagnostic tool, or therapeutic agent highlights the importance of reproducible cardiac differentiation. Notably, the original tissue in which nuclear reprogramming is performed influences the differentiation potential of the resulting iPS product (Fig. 1). Initially, Marchetto et al. [65] described how neural stem cells that had been reprogrammed to fulfill pluripotency criteria (e.g., in vitro differentiation and in vivo teratoma formation) displayed incomplete suppression of neural-specific genes and partial induction of early embryonic genes. These results were confirmed by Ghosh et al. in an extended array of human reprogrammed cells derived from fetal or newborn fibroblasts, adipose stem cells, and keratinocytes, each of them maintaining a transcriptional memory corresponding to the tissue of origin [66]. Upregulation of lineage-specific genes in the ground state predicted possible downstream effects on the differentiation capacities of the bioengineered iPS lines. This observation was confirmed when mesoderm reprogrammed cells were shown to give rise to osteogenic cells more efficiently than blood-derived iPS cells, thereby yielding additional hematopoietic colo- nies [32]. Therefore, somatic cells reprogrammed by transcription factor induction favorably differentiate along lineages related to the donor cell (Fig. 1) [32]. DNA methylation patterns in promoter regions and histone acetylation, both components of the epigenetic state of the cell, have been shown to correlate with the propensity of differentiation after reprogramming adding epigenetic memory as an important level of regulation in the bioengineering process $[31,32]$. Furthermore, the transcriptional fingerprint of iPS cells derived from distinct origins reveals gene expression patterns characteristic of the original cell source [31]. In an attempt to erase residual epigenetic and transcriptional memories from bioengineered pluripotent cells, two methods have been described. According to Polo et al. and in agreement with previous work describing reprogramming as a process that continues in vitro for several passages [33], continuous cell division resolves transcriptional and epigenetic differences equilibrating the differentiation capacity of iPS cells derived from different tissue sources [31] (Fig. 1). In a different approach, Kim et al. used epigenetic modifiers to homogenize differentiation capacities from iPS cells with various origins [32] (Fig. 1). Therefore, the residual memory of source cytotype is not permanent and epigenetic modification can provide an effective strategy to alter the differentiation capacity of reprogrammed stem cells.

Since cells demonstrated to be pluripotent by current standards may display dissimilarities in a subsequent differentiation capacity, propensity for lineage specification may be required to accurately predict the extent of nuclear reprogramming. Whether preferential differentiation capacity is an advantage or a detriment depends on the

Table 1 Multimodal characterization of cardiac differentiation potential of iPS cells

\begin{tabular}{|c|c|c|c|c|c|c|c|c|c|c|c|}
\hline Tissue source & $\begin{array}{l}\text { Gene } \\
\text { expression }\end{array}$ & IF & FACS & Ultra-structure & $\begin{array}{l}\text { Patch } \\
\text { clamp }\end{array}$ & $\begin{array}{l}\text { Calcium } \\
\text { imaging }\end{array}$ & MEA & $\begin{array}{l}\text { Pharmacol } \\
\text { response }\end{array}$ & $\begin{array}{l}\text { In vivo } \\
\text { chimerism }\end{array}$ & $\begin{array}{l}\text { In situ } \\
\text { contribution }\end{array}$ & Ref. no \\
\hline Mouse fibroblast & $\sqrt{ }$ & $\sqrt{ }$ & & & $\sqrt{ }$ & & & $\sqrt{ }$ & & & [57] \\
\hline Mouse fibroblast & $\sqrt{ }$ & $\sqrt{ }$ & & $\sqrt{ }$ & $\sqrt{ }$ & $\sqrt{ }$ & & & $\sqrt{ }$ & & {$[58]$} \\
\hline Mouse fibroblast & $\sqrt{ }$ & $\sqrt{ }$ & & & & $\sqrt{ }$ & & & $\sqrt{ }$ & & [59] \\
\hline Mouse fibroblast & $\sqrt{ }$ & $\sqrt{ }$ & & & & $\sqrt{ }$ & $\sqrt{ }$ & $\sqrt{ }$ & & & {$[60]$} \\
\hline $\begin{array}{l}\text { Mouse and human } \\
\text { fibroblast }\end{array}$ & $\sqrt{ }$ & $\sqrt{ }$ & & & & & & & & $\sqrt{ }$ & [55] \\
\hline Mouse fibroblast & $\sqrt{ }$ & $\sqrt{ }$ & $\sqrt{ }$ & & $\sqrt{ }$ & & & & & & [20] \\
\hline Mouse fibroblast & $\sqrt{ }$ & $\sqrt{ }$ & & & & & & & $\sqrt{ }$ & $\sqrt{ }$ & [29] \\
\hline Mouse fibroblast & $\sqrt{ }$ & $\sqrt{ }$ & & & & & $\sqrt{ }$ & $\sqrt{ }$ & & & {$[61]$} \\
\hline Mouse fibroblast & $\sqrt{ }$ & $\sqrt{ }$ & & & & $\sqrt{ }$ & & & $\sqrt{ }$ & & {$[21]$} \\
\hline Human fibroblast & $\sqrt{ }$ & $\sqrt{ }$ & $\sqrt{ }$ & & & & & $\sqrt{ }$ & & & {$[56]$} \\
\hline Human fibroblast & $\sqrt{ }$ & $\sqrt{ }$ & & & & & $\sqrt{ }$ & $\sqrt{ }$ & & & {$[62]$} \\
\hline Human fibroblast & $\sqrt{ }$ & $\sqrt{ }$ & & & & & & $\sqrt{ }$ & & & {$[63]$} \\
\hline Human fibroblast & $\sqrt{ }$ & $\sqrt{ }$ & & & & & $\sqrt{ }$ & $\sqrt{ }$ & & & [64] \\
\hline
\end{tabular}

IF immunofluorescence, FACS fluorescence activated cell sorting, MEA multielectrode array, Pharmacol pharmacological 
Fig. 1 Strategies to standardize the differentiation capacity of reprogrammed cells. Residual epigenetic and transcriptional memories cause bioengineered progeny to have a biased differentiation propensity, independent of acquired pluripotency as defined by sporadic three germ layer differentiation capacity. Strategies that include continuous passaging or treatment with epigenetic modulators are sufficient to erase cellular memory of the somatic cell origin and ensure unbiased differentiation capacity of bioengineered iPS cells

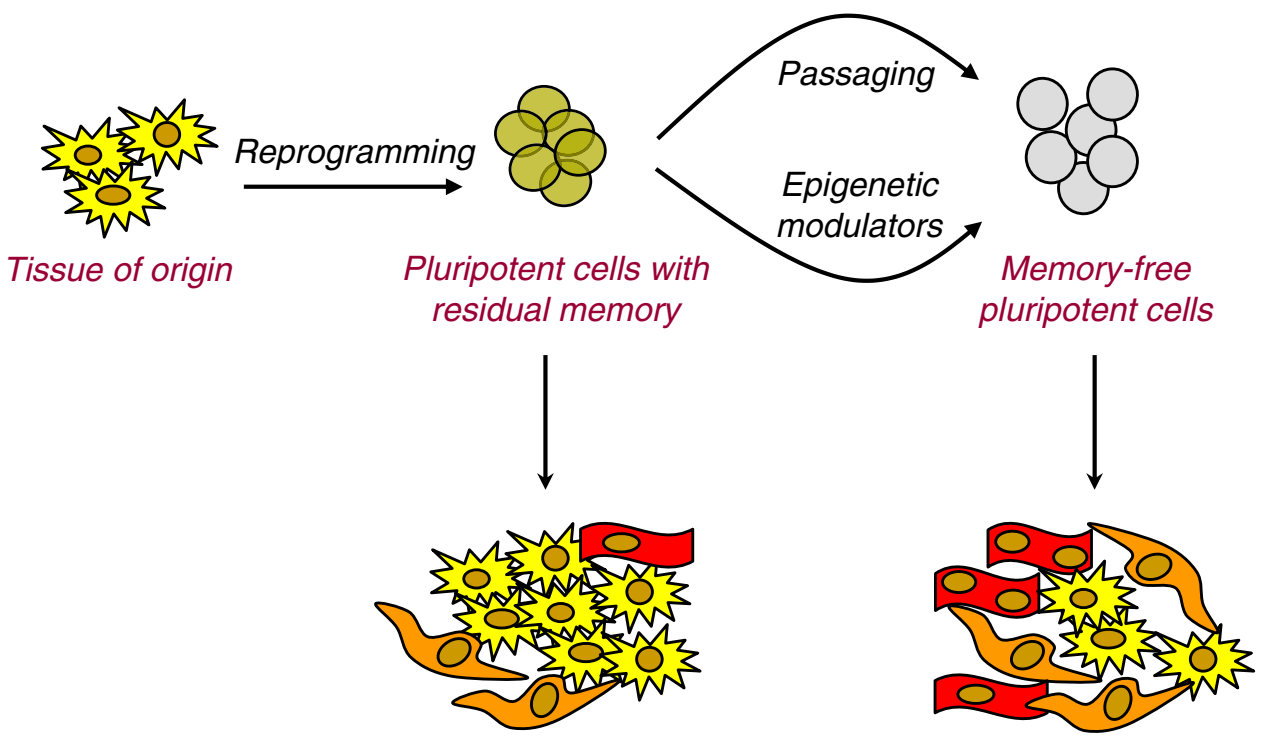

Biased differentiation
Unbiased differentiation application of the derived iPS cells. As for cell types difficult to obtain in vitro, the impact of residual memory may benefit subsequent derivation of differentiated tissues if iPS cells are derived from related cell types. On the other hand, standardization of pluripotency will be required for basic biological applications or when a non-related tissue of origin is bioengineered in order to obtain a defined cytotype. In summary, tissue of origin may bias the differentiation potential of iPS cells due to residual transcriptional and epigenetic memories that are latent in the pluripotent ground state.

\section{Reprogramming Strategy}

\section{Exogenous Transgenes}

Distilling down from an array of pluripotency-related genes, four factors were initially demonstrated to be sufficient to re-establish the ground state upon transduction in mouse somatic cells [3]. A slightly different combination was later shown to work in human cells, with two of the factors being maintained as a core (namely Sox 2 and Oct4) and two different transcription factors being interchangeable (either Klf4 and c-Myc or Lin28 and Nanog) [7]. With refinement of the protocols, the oncogene c-Myc, was recognized to be dispensable [40] or replaceable by another family member, low transformation capacity L-Myc, limiting the oncogenicity of the derived iPS cells [67]. In an attempt to minimize the number of required factors, small molecules have been assayed for downstream effects involved in the ground state resetting process. Notably, specific cell types with high intrinsic expression levels of stemness factors have been used in an attempt to simplify the reprogramming process [68]. The most dramatic example has been the reprogramming of neural cells with only Oct4 [69]. Thus, a targeted strategy to minimize the burden of ectopic transgenes is devised by complementing the factors required for reprogramming iPS cells.

Regardless of the specific factors used in this induction of undifferentiated phenotype, sustained expression has been shown to be necessary for a limited time, reprogrammed cells becoming independent of exogenous transgenes a few weeks following transduction [70]. Depending on the expression platform utilized to initiate nuclear reprogramming, persistent expression of stemness factors may be responsible for unintentional secondary effects. In this regard, in vitro endodermal differentiation in the presence of the reprogramming factors beyond the pluripotency induction process has been shown to be impaired when compared to reprogrammed cells from which exogenous transgenes had been excised [71]. Indeed, parental iPS cells containing a polycistronic vector that encoded the four reprogramming factors showed a diminished capacity to respond to soluble growth factor-differentiation cues while their transgene-free progeny responded to the same protocol upregulating key endodermal transcription factors [71]. A similar outcome was observed for ectoderm and mesoderm tissue, in both cases revealing that differentiation was enhanced by excision of the reprogramming factors [71].

Indeed, a single factor of the bioengineering kit might have a significant effect on the differentiation capacity of iPS cells. In particular, the presence of the oncogene c-Myc during the reprogramming process impairs cardiac differentiation capacity in bioengineered pluripotent cells [59] while the absence of this factor leads to reprogrammed progeny with a high cardiogenic propensity indicated by 
the ability to give rise to cardiomyocytes characterized by sarcomeric structures, calcium currents, spontaneous beating activity, and high cardiac gene expression [58]. An insight into the underlying mechanism has been obtained using trichostatin $\mathrm{A}$, a histone deacetylase inhibitor, which facilitated myocardial differentiation despite c-Myc exposure in an iPS line showing low levels of cardiac gene expression and beating activity prior to treatment [72]. This study reinforces the importance of the epigenetic acetylation state as a component of the residual memory. Considering the data shown in this report, the reprogramming strategy may have an epigenetic imprint that modulates downstream differentiation properties. Another explanation would be the repression exerted by Myc on endoderm differentiation pathways that are requited for proper mesoderm differentiation [73]. According to this study, cMyc inhibits primitive endoderm specification by repressing Gata6 at the transcriptional level impacting downstream differentiation events linked to mesoderm formation. In summary, exposure and combination of exogenous transgenes used for pluripotency induction may have a direct or indirect effect on the differentiation potential of the bioengineered progeny.

\section{Facilitators of Reprogramming}

Designing a complementary strategy to optimize the ratelimiting steps of nuclear reprogramming not only offers advantages for the overall efficiency of iPS derivation but has an influence on the quality and differentiation potential of the reprogrammed cells [32, 74]. Facilitators are small molecules or conditions that improve the efficacy of nuclear reprogramming. An example of a condition favoring bioengineering is hypoxia. Decreasing oxygen levels to $5 \%$ creates an environment that provokes a complex rearrangement of gene expression profile leading to increased induction of reprogramming in human fibroblasts [15].

Important to the epigenetic state, histone acetylation and methylation regulate the accessibility of the transcription machinery to the genetic blueprint within the parental cell. In this context, inhibition of histone deacetylase or DNA-methyl transferase using epigenetic modifiers valproic acid (VPA) or 5-aza-cytidine (5-AZA) has benefited the chromatin remodeling and increased the efficiency of standardized reprogramming protocols $[16,17]$. Characterization of the epigenetic state has revealed a fundamental component in determining the fate of bioengineered cells. This has led to the use of epigenetic modulators such as VPA, 5-AZA, or trichostatin A to revert repressive residual epigenetic memory in order to increase the range and reproducibility of tissues derived from a reprogrammed line, homogenizing and improving differentiation potential $[32,72]$.

\section{Conclusion}

Together, these observations lead to the hypothesis that beyond induction of the pluripotency state, the differentiation properties of the engineered cells also need to be carefully characterized and, if needed, standardized. Residual memory retained from the original cell source should be considered as a possible limitation for broad differentiation profiles, although it could also be a useful feature when the tissue of interest or a closely related one is readily accessible. Optimized reprogramming strategies may resolve the persistent effects due to residual transgene expression while strategies such as continuous passaging and use of epigenetic modulators may be useful to homogenize differentiation capacity despite the tissue of origin used for iPS cell production. Collectively, nuclear reprogramming strategies designed to achieve both functional pluripotency while promoting tissue-specific predilections will continue to accelerate the focused effort of discovery, translation, and applications for specialized fields such as cardiovascular regenerative medicine.

Acknowledgments Work in the laboratory of the authors was supported by the National Institutes of Health, Marriott Individualized Medicine Program, Marriott Heart Disease Research Program, and Mayo Clinic.

Open Access This article is distributed under the terms of the Creative Commons Attribution Noncommercial License which permits any noncommercial use, distribution, and reproduction in any medium, provided the original author(s) and source are credited.

\section{References}

1. Martin, G. R. (1981). Isolation of a pluripotent cell line from early mouse embryos cultured in medium conditioned by teratocarcinoma stem cells. Proceedings of the National Academy of Sciences of the United States of America, 78, 7634-7638.

2. Thomson, J. A., Itskovitz-Eldor, J., Shapiro, S. S., Waknitz, M. A., Swiergiel, J. J., Marshall, V. S., et al. (1998). Embryonic stem cell lines derived from human blastocysts. Science, 282, 11451147.

3. Takahashi, K., \& Yamanaka, S. (2006). Induction of pluripotent stem cells from mouse embryonic and adult fibroblast cultures by defined factors. Cell, 126, 663-676.

4. Terzic, A., \& Nelson, T. J. (2010). Regenerative medicine advancing health care 2020. Journal of the American College of Cardiology, 55, 2254-2257.

5. Nelson, T. J., Behfar, A., Yamada, S., Martinez-Fernandez, A., \& Terzic, A. (2009). Stem cell platforms for regenerative medicine. Clinical and Translational Science, 2, 222-227.

6. Takahashi, K., Tanabe, K., Ohnuki, M., Narita, M., Ichisaka, T., Tomoda, K., et al. (2007). Induction of pluripotent stem cells from adult human fibroblasts by defined factors. Cell, 131, 861-872.

7. Yu, J., Vodyanik, M. A., Smuga-Otto, K., Antosiewicz-Bourget, J., Frane, J. L., Tian, S., et al. (2007). Induced pluripotent stem cell lines derived from human somatic cells. Science, 318, 1917-1920. 
8. Aasen, T., Raya, A., Barrero, M. J., Garreta, E., Consiglio, A., Gonzalez, F., et al. (2008). Efficient and rapid generation of induced pluripotent stem cells from human keratinocytes. Nature Biotechnology, 26, 1276-1284.

9. Sun, N., Panetta, N. J., Gupta, D. M., Wilson, K. D., Lee, A., Jia, F., et al. (2009). Feeder-free derivation of induced pluripotent stem cells from adult human adipose stem cells. Proceedings of the National Academy of Sciences of the United States of America, 106, 15720-15725.

10. Loh, Y. H., Agarwal, S., Park, I. H., Urbach, A., Huo, H., Heffner, G. C., et al. (2009). Generation of induced pluripotent stem cells from human blood. Blood, 113, 5476-5479.

11. Seki, T., Yuasa, S., Oda, M., Egashira, T., Yae, K., Kusumoto, D., et al. (2010). Generation of induced pluripotent stem cells from human terminally differentiated circulating T cells. Cell Stem Cell, 7, 11-14.

12. Staerk, J., Dawlaty, M. M., Gao, Q., Maetzel, D., Hanna, J., Sommer, C. A., et al. (2010). Reprogramming of human peripheral blood cells to induced pluripotent stem cells. Cell Stem Cell, 7, 20-24.

13. Loh, Y. H., Hartung, O., Li, H., Guo, C., Sahalie, J. M., Manos, P. D., et al. (2010). Reprogramming of $\mathrm{T}$ cells from human peripheral blood. Cell Stem Cell, 7, 15-19.

14. Mali, P., Chou, B. K., Yen, J., Ye, Z., Zou, J., Dowey, S., et al. (2010). Butyrate greatly enhances derivation of human induced pluripotent stem cells by promoting epigenetic remodeling and the expression of pluripotency-associated genes. Stem Cells, 28, 713-720.

15. Yoshida, Y., Takahashi, K., Okita, K., Ichisaka, T., \& Yamanaka, S. (2009). Hypoxia enhances the generation of induced pluripotent stem cells. Cell Stem Cell, 5, 237-241.

16. Huangfu, D., Maehr, R., Guo, W., Eijkelenboom, A., Snitow, M., Chen, A. E., et al. (2008). Induction of pluripotent stem cells by defined factors is greatly improved by small-molecule compounds. Nature Biotechnology, 26, 795-797.

17. Mikkelsen, T. S., Hanna, J., Zhang, X., Ku, M., Wernig, M., Schorderet, P., et al. (2008). Dissecting direct reprogramming through integrative genomic analysis. Nature, 454, 49-55.

18. Tashiro, K., Inamura, M., Kawabata, K., Sakurai, F., Yamanishi, K., Hayakawa, T., et al. (2009). Efficient adipocyte and osteoblast differentiation from mouse induced pluripotent stem cells by adenoviral transduction. Stem Cells, 27, 1802-1811.

19. Niwa, A., Umeda, K., Chang, H., Saito, M., Okita, K., Takahashi, K., et al. (2009). Orderly hematopoietic development of induced pluripotent stem cells via flk-1(+) hemoangiogenic progenitors. Journal of Cellular Physiology, 221, 367-377.

20. Narazaki, G., Uosaki, H., Teranishi, M., Okita, K., Kim, B., Matsuoka, S., et al. (2008). Directed and systematic differentiation of cardiovascular cells from mouse induced pluripotent stem cells. Circulation, 118, 498-506.

21. Schenke-Layland, K., Rhodes, K. E., Angelis, E., Butylkova, Y., Heydarkhan-Hagvall, S., Gekas, C., et al. (2008). Reprogrammed mouse fibroblasts differentiate into cells of the cardiovascular and hematopoietic lineages. Stem Cells, 26, 1537-1546.

22. Senju, S., Haruta, M., Matsunaga, Y., Fukushima, S., Ikeda, T., Takahashi, K., et al. (2009). Characterization of dendritic cells and macrophages generated by directed differentiation from mouse induced pluripotent stem cells. Stem Cells, 27, 1021-1031.

23. Maehr, R., Chen, S., Snitow, M., Ludwig, T., Yagasaki, L., Goland, R., et al. (2009). Generation of pluripotent stem cells from patients with type 1 diabetes. Proceedings of the National Academy of Sciences of the United States of America, 106, 15768-15773

24. Song, Z., Cai, J., Liu, Y., Zhao, D., Yong, J., Duo, S., et al. (2009). Efficient generation of hepatocyte-like cells from human induced pluripotent stem cells. Cell Research, 19, 1233-1242.

25. Buchholz, D. E., Hikita, S. T., Rowland, T. J., Friedrich, A. M., Hinman, C. R., Johnson, L. V., et al. (2009). Derivation of functional retinal pigmented epithelium from induced pluripotent stem cells. Stem Cells, 27, 2427-2434.

26. Karumbayaram, S., Novitch, B. G., Patterson, M., Umbach, J. A., Richter, L., Lindgren, A., et al. (2009). Directed differentiation of human-induced pluripotent stem cells generates active motor neurons. Stem Cells, 27, 806-811.

27. Carvajal-Vergara, X., Sevilla, A., D'Souza, S. L., Ang, Y. S., Schaniel, C., Lee, D. F., et al. (2010). Patient-specific induced pluripotent stem-cell-derived models of LEOPARD syndrome. Nature, 465, 808-812.

28. Moretti, A., Bellin, M., Welling, A., Jung, C. B., Lam, J. T., BottFlügel, L., et al. (2010). Patient-specific induced pluripotent stemcell models for Long-QT Syndrome. The New England Journal of Medicine, 363, 1397-1409.

29. Nelson, T. J., Martinez-Fernandez, A., Yamada, S., Perez-Terzic, C., Ikeda, Y., \& Terzic, A. (2010). Repair of acute myocardial infarction by human stemness factors induced pluripotent stem cells. Circulation, 120, 408-416.

30. Nelson, T. J., Martinez-Fernandez, A., \& Terzic, A. (2010). Induced pluripotent stem cells: developmental biology to regenerative medicine. Nature Reviews Cardiology, 7, 700-710.

31. Polo, J. M., Liu, S., Figueroa, M. E., Kulalert, W., Eminli, S., Tan, K. Y., et al. (2010). Cell type of origin influences the molecular and functional properties of mouse induced pluripotent stem cells. Nature Biotechnology, 28, 848-855.

32. Kim, K., Doi, A., Wen, B., Ng, K., Zhao, R., Cahan, P., et al. (2010). Epigenetic memory in induced pluripotent stem cells. Nature, 467, 285-290.

33. Chin, M. H., Mason, M. J., Xie, W., Volinia, S., Singer, M., Peterson, C., et al. (2009). Induced pluripotent stem cells and embryonic stem cells are distinguished by gene expression signatures. Cell Stem Cell, 5, 111-123.

34. Okita, K., Ichisaka, T., \& Yamanaka, S. (2007). Generation of germline-competent induced pluripotent stem cells. Nature, 448 , 313-317.

35. Boland, M. J., Hazen, J. L., Nazor, K. L., Rodriguez, A. R., Gifford, W., Martin, G., et al. (2009). Adult mice generated from induced pluripotent stem cells. Nature, 461, 91-94.

36. Cyranoski, D. (2008). Stem cells: 5 things to know before jumping on the iPS bandwagon. Nature, 452, 406-408.

37. Meissner, A., Wernig, M., \& Jaenisch, R. (2007). Direct reprogramming of genetically unmodified fibroblasts into pluripotent stem cells. Nature Biotechnology, 25, 1177-1181.

38. Hanna, J., Markoulaki, S., Schorderet, P., Carey, B. W., Beard, C., Wernig, M., et al. (2008). Direct reprogramming of terminally differentiated mature B lymphocytes to pluripotency. Cell, 133, 250-264.

39. Hanna, J., Wernig, M., Markoulaki, S., Sun, C. W., Meissner, A., Cassady, J. P., et al. (2007). Treatment of sickle cell anemia mouse model with ips cells generated from autologous skin. Science, $318,1920-1923$.

40. Nakagawa, M., Koyanagi, M., Tanabe, K., Takahashi, K., Ichisaka, T., Aoi, T., et al. (2008). Generation of induced pluripotent stem cells without myc from mouse and human fibroblasts. Nature Biotechnology, 26, 101-106.

41. Aoi, T., Yae, K., Nakagawa, M., Ichisaka, T., Okita, K., Takahashi, K., et al. (2008). Generation of pluripotent stem cells from adult mouse liver and stomach cells. Science, 321, 699-702.

42. Stadtfeld, M., Brennand, K., \& Hochedlinger, K. (2008). Reprogramming of pancreatic beta cells into induced pluripotent stem cells. Current Biology, 18, 890-894.

43. Silva, J., Barrandon, O., Nichols, J., Kawaguchi, J., Theunissen, T. W., \& Smith, A. (2009). Promotion of reprogramming to ground state pluripotency by signal inhibition. PLoS Biology, 6, e253.

44. Kim, J. B., Zaehres, H., Wu, G., Gentile, L., Ko, K., Sebastiano, V., et al. (2009). Pluripotent stem cells induced from adult neural 
stem cells by reprogramming with two factors. Nature, 454, 646650 .

45. Eminli, S., Foudi, A., Stadtfeld, M., Maherali, N., Ahfeldt, T., Mostoslavsky, G., et al. (2009). Differentiation stage determines potential of hematopoietic cells for reprogramming into induced pluripotent stem cells. Nature Genetics, 41, 968-976.

46. Hanna, J., Saha, K., Pando, B., van Zon, J., Lengner, C. J., Creyghton, M. P., et al. (2009). Direct cell reprogramming is a stochastic process amenable to acceleration. Nature, 462, 595601.

47. Byrne, J. A., Nguyen, H. N., \& Reijo Pera, R. A. (2009). Enhanced generation of induced pluripotent stem cells from a subpopulation of human fibroblasts. PLoS ONE, 4, e7118.

48. Miura, K., Okada, Y., Aoi, T., Okada, A., Takahashi, K., Okita, K., et al. (2009). Variation in the safety of induced pluripotent stem cell lines. Nature Biotechnology, 27, 743-745.

49. Park, I. H., Arora, N., Huo, H., Maherali, N., Ahfeldt, T., Shimamura, A., et al. (2008). Disease-specific induced pluripotent stem cells. Cell, 134, 877-886.

50. Ye, Z., Zhan, H., Mali, P., Dowey, S., Williams, D. M., Jang, Y. Y., et al. (2009). Human induced pluripotent stem cells from blood cells of healthy donors and patients with acquired blood disorders. Blood, 114, 5473-5480.

51. Dimos, J. T., Rodolfa, K. T., Niakan, K. K., Weisenthal, L. M., Mitsumoto, H., Chung, W., et al. (2008). Induced pluripotent stem cells generated from patients with als can be differentiated into motor neurons. Science, 321, 1218-1221.

52. Raya, A., Rodriguez-Piza, I., Guenechea, G., Vassena, R., Navarro, S., Barrero, M. J., et al. (2009). Disease-corrected haematopoietic progenitors from fanconi anaemia induced pluripotent stem cells. Nature, 460, 53-59.

53. Ebert, A. D., Yu, J., Rose, F. F., Jr., Mattis, V. B., Lorson, C. L., Thomson, J. A., et al. (2009). Induced pluripotent stem cells from a spinal muscular atrophy patient. Nature, 457, 277-280.

54. Lee, G., Papapetrou, E. P., Kim, H., Chambers, S. M., Tomishima, M. J., Fasano, C. A., et al. (2009). Modelling pathogenesis and treatment of familial dysautonomia using patient-specific ipscs. Nature, 461, 402-406.

55. Moretti, A., Bellin, M., Jung, C. B., Thies, T. M., Takashima, Y., Bernshausen, A., et al. (2010). Mouse and human induced pluripotent stem cells as a source for multipotent Is11+ cardiovascular progenitors. The FASEB Journal, 24, 700-711.

56. Gai, H., Leung, E. L., Costantino, P. D., Aguila, J. R., Nguyen, D. M., Fink, L. M., et al. (2009). Generation and characterization of functional cardiomyocytes using induced pluripotent stem cells derived from human fibroblasts. Cell Biology International, 33, 1184-11893.

57. Kuzmenkin, A., Liang, H., Xu, G., Pfannkuche, K., Eichhorn, H., Fatima, A., et al. (2009). Functional characterization of cardiomyocytes derived from murine induced pluripotent stem cells in vitro. The FASEB Journal, 23, 4168-4180.

58. Martinez-Fernandez, A., Nelson, T. J., Yamada, S., Reyes, S., Alekseev, A. E., Perez-Terzic, C., et al. (2009). iPS programmed without c-MYC yield proficient cardiogenesis for functional heart chimerism. Circulation Research, 105, 648-656.

59. Martinez-Fernandez, A., Nelson, T. J., Ikeda, Y., \& Terzic, A. (2010). c-MYC independent nuclear reprogramming favors cardiogenic potential of induced pluripotent stem cells. Journal of Cardiovascular Translational Research, 3, 13-23.
60. Mauritz, C., Schwanke, K., Reppel, M., Neef, S., Katsirntaki, K., Maier, L. S., et al. (2008). Generation of functional murine cardiac myocytes from induced pluripotent stem cells. Circulation, 118 , 507-517.

61. Pfannkuche, K., Liang, H., Hannes, T., Xi, J., Fatima, A., Nguemo, F., et al. (2009). Cardiac myocytes derived from murine reprogrammed fibroblasts: intact hormonal regulation, cardiac ion channel expression and development of contractility. Cellular Physiology and Biochemistry, 24, 73-86.

62. Yokoo, N., Baba, S., Kaichi, S., Niwa, A., Mima, T., Doi, H., et al. (2009). The effects of cardioactive drugs on cardiomyocytes derived from human induced pluripotent stem cells. Biochemical and Biophysical Research Communications, 387, 482-488.

63. Zhang, J., Wilson, G. F., Soerens, A. G., Koonce, C. H., Yu, J., Palecek, S. P., et al. (2009). Functional cardiomyocytes derived from human induced pluripotent stem cells. Circulation Research, 104, e30-e41.

64. Zwi, L., Caspi, O., Arbel, G., Huber, I., Gepstein, A., Park, I. H., et al. (2009). Cardiomyocyte differentiation of human induced pluripotent stem cells. Circulation, 120, 1513-1523.

65. Marchetto, M. C., Yeo, G. W., Kainohana, O., Marsala, M., Gage, F. H., \& Muotri, A. R. (2009). Transcriptional signature and memory retention of human-induced pluripotent stem cells. PLoS ONE, 4, e7076.

66. Ghosh, Z., Wilson, K. D., Wu, Y., Hu, S., Quertermous, T., \& Wu, J. C. (2010). Persistent donor cell gene expression among human induced pluripotent stem cells contributes to differences with human embryonic stem cells. PLoS ONE, 5, e8975.

67. Nakagawa, M., Takizawa, N., Narita, M., Ichisaka, T., \& Yamanaka, S. (2010). Promotion of direct reprogramming by transformation-deficient Myc. Proceedings of the National Academy of Sciences of the United States of America, 107, 14152-14157.

68. Lyssiotis, C. A., Foreman, R. K., Staerk, J., Garcia, M., Mathur, D., Markoulaki, S., et al. (2009). Reprogramming of murine fibroblasts to induced pluripotent stem cells with chemical complementation of klf4. Proceedings of the National Academy of Sciences, 106, 8912-8917.

69. Kim, J. B., Zaehres, H., Arauzo-Bravo, M. J., \& Scholer, H. R. (2009). Generation of induced pluripotent stem cells from neural stem cells. Nature Protocols, 4, 1464-1470.

70. Okita, K., Nakagawa, M., Hyenjong, H., Ichisaka, T., \& Yamanaka, S. (2008). Generation of mouse induced pluripotent stem cells without viral vectors. Science, 322, 949-953.

71. Sommer, C. A., Gianotti Sommer, A., Longmire, T. A., Christodoulou, C., Thomas, D. D., Gostissa, M., et al. (2009). Excision of reprogramming transgenes improves the differentiation potential of ips cells generated with a single excisable vector. Stem Cells, 28, 64-67.

72. Kaichi, S., Hasegawa, K., Takaya, T., Yokoo, N., Mima, T., Kawamura, T., et al. (2010). Cell line-dependent differentiation of induced pluripotent stem cells into cardiomyocytes in mice. Cardiovascular Research, 88, 314-323.

73. Smith, K. N., Singh, A. M., \& Dalton, S. (2010). Myc represses primitive endoderm differentiation in pluripotent stem cells. Cell Stem Cell, 7, 343-354.

74. Shi, Y., Desponts, C., Do, J. T., Hahm, H. S., Schöler, H. R., \& Ding, S. (2008). Induction of pluripotent stem cells from mouse embryonic fibroblasts by Oct4 and Klf4 with small-molecule compounds. Cell Stem Cell, 3, 568-574. 